\title{
Article \\ Blood Wettability of Different Dental Implant Surfaces after Different Pre-Treatments: Ultrasonic Instrumentation, Platelet-Rich Fibrin Coating, and Acid Etching. An In Vitro Study
}

\author{
Lorenzo Bevilacqua $^{1}$, Francesco Faccioni ${ }^{1, *}$, Davide Porrelli ${ }^{1}$ (D), Paolo Faccioni ${ }^{2}$, Francesco Rusin ${ }^{1}$, \\ Andrea Frassetto ${ }^{1}$ and Michele Maglione ${ }^{1}$ (D) \\ 1 Department of Medicine, Surgery and Health Sciences, University of Trieste, 34127 Trieste TS, Italy; \\ 1.bevilacqua@fmc.units.it (L.B.); dporrelli@units.it (D.P.); francesco.rusin@asugi.sanita.fvg.it (F.R.); \\ andrea.frassetto@asugi.sanita.fvg.it (A.F.); m.maglione@fmc.units.it (M.M.) \\ 2 Specialist in Orthodontics—Freelance Professional, 37121 Verona VR, Italy; paolo.faccioni@univr.it \\ * Correspondence: francesco.faccioni@pec-mail.eu
}

check for updates

Citation: Bevilacqua, L.; Faccioni, F.; Porrelli, D.; Faccioni, P.; Rusin, F.; Frassetto, A.; Maglione, M. Blood Wettability of Different Dental Implant Surfaces after Different Pre-Treatments: Ultrasonic Instrumentation, Platelet-Rich Fibrin Coating, and Acid Etching. An In Vitro Study. Appl. Sci. 2021, 11, 1433. https://doi.org/10.3390/app11041433

Academic Editor: Gaetano Marenzi

Received: 24 December 2020

Accepted: 2 February 2021

Published: 5 February 2021

Publisher's Note: MDPI stays neutral with regard to jurisdictional claims in published maps and institutional affiliations.

Copyright: (c) 2021 by the authors. Licensee MDPI, Basel, Switzerland. This article is an open access article distributed under the terms and conditions of the Creative Commons Attribution (CC BY) license (https:// creativecommons.org/licenses/by/ $4.0 /)$.

\begin{abstract}
Background: The blood wettability of titanium implant surfaces favors primary osseointegration and tissue healing in peri-implantitis. The current study aims to evaluate this property on the main different kinds of surfaces, brand new and after treatments. Methods: grade IV titanium disks were used, five machined, five laser-treated, five sandblasted. The experiment was on four steps. Between each step, specimens were sterilized. At the end of each step, a $4 \mu \mathrm{L}$ blood drop was put on the samples, and contact angles were calculated. The steps consisted of -1 : no treatment; 2: surface instrumentation with an ultrasonic titanium tip; 3: platelet-rich fibrin (PRF) coating and drying with sterile gauze; 4: etching with phosphoric acid, rinse and saline solution and air-drying. At the end of each phase, a blood drop was placed on the surfaces. Blood for PRF preparation and for calculation of contact angles was collected from a single source. Results: average wettability decreased after instrumentation, and increased after the PRF application to a superior level both to the first and second steps. The highest wettability was obtained after etching. This trend is statistically significant for machined and sandblasted surfaces. Conclusions: In the clinical environment, PRF and phosphoric acid used for conditioning exposed implant surfaces can be used for the healing of peri-implant tissues.
\end{abstract}

Keywords: ultrasonic; platelet-rich fibrin; wettability; peri-implantitis; etching; phosphoric acid; titanium; implant surface; roughness

\section{Introduction}

It is demonstrated that dental implant surface microgeometry influences platelet response [1]. In particular, when platelets interact with the implant surface, they release many growth factors and cytokines (TGF- $\beta$, TNF, EDGF), creating a chemical gradient that activates surrounding platelets [2]. Implant surfaces on the market can be subdivided into two macro-categories: machined smooth surfaces and rough surfaces. A rough surface is created starting from a machined surface, applying surface modification: etching, sandblasting or laser-treatment [3].

Surface modification technique using a laser allows obtaining surfaces with a high grade of superficial purity (challenging to obtain in sandblasted and acid-etched surfaces). With the laser technique, an extremely regular surface is obtained [4]. The surface is characterized by micro pits that sustain cell adhesion and proliferation, and by a surface roughness that inhibits bacterial adhesion and biofilm formation $[4,5]$.

Another factor able to influence peri-implant bone healing is blood wettability. In vitro studies demonstrated that adhesion, spreading, and proliferation of osteoprogenitor cells 
are more rapid on a more wettable surface than on a less wettable surface [6]. Wettability is the ability of a liquid to maintain contact with a solid surface [7]. These aforementioned aspects have the following practical effect: when adhesion forces are superior to cohesion forces, the liquid wets the solid surface more $[7,8]$.

Platelet concentrates are used as topical agents to improve surgical wound healing. Among other platelet concentrates, platelet-rich fibrin (PRF) has emerged as a valid choice. It has been demonstrated that PRF can be used in bone regeneration. Its production technique [9] is simple and does not require biochemical blood manipulation. PRF is obtained by blood sampling the patient and then centrifuging the blood sample. After centrifugation, blood components are separated and PRF can be extracted. Its use must be contextual to its preparation because its conservation is impossible. There are many clinical studies in the literature from case reports to research on population samples and also systematic reviews in which PRF was used alone or in combination with other medications in oral surgery (for maxillary sinus lift [10-14], treatment of maxillary sinus perforation [15], ridge preservation [16-21]), implant dentistry (to increase implant stability and favour osseointegration [18,22], for immediate implant placing [23,24]), periodontology (periodontal and soft tissue repair $[16,25,26]$ ) and peri-implantitis treatment (peri-implant keratinized mucosa width increase [27] and retrograde peri-implantitis treatment [28]).

The current study aimed to evaluate the blood wettability of grade IV titanium sample surfaces with different microgeometry: wettability was calculated before and after instrumentation with an ultrasonic grade IV titanium tip, after instrumentation with an ultrasonic grade IV titanium tip, after instrumentation and PRF pre-treatment, and after instrumentation and pre-etching with $38 \%$ phosphoric acid.

\section{Materials and Methods}

The current study was conducted with blood sampling from a single source: a caucasian male donor with Ethical Committee permission n84/2017 (University of Trieste). The volunteer signed a specific, informed consent for blood sampling and treatment of his blood for scientific purposes. Moreover, the volunteer certified the absence of systemic and/or infectious pathologies, allergies, and did not take medications. Lastly, he committed to not take drugs and/or medications during the study period. Blood did not subdue biochemical manipulation. An amount of $2 \mathrm{cl}$ was used for calculating the angle on the implant surface of specimens (Figure 1) without PRF. Additionally, $10 \mathrm{cl}$ was used for the preparation of the PRF.

For this purpose, blood was collected in an empty test tube placed in the appropriate centrifuge (Spectrafuge ${ }^{\circledR} 6 \mathrm{c}$-Labnet International ${ }^{\circledR}$, Inc., Edison, NJ, USA) with $8.5 \mathrm{~cm}$ centrifuging radius. In order to obtain PRF, blood centrifugation lasted $10 \mathrm{~min}$ at 3000 r.p.m. [9]. An amount of $2 \mathrm{cl}$ of the blood sample was used to calculate the contact angle between the implant surface and blood of the titanium samples after the PRF application and $2 \mathrm{cl}$ of blood sample was used after phosphoric acid (38\%) etching. Blood collection was repeated, when necessary, at different times to avoid coagulation. In the current study, a Leica MZ16 ${ }^{\circledR}$ (Leica ${ }^{\circledR}$, Wetzlar, Germany) optical microscope with Leica FDC $320^{\circledR}$ camera (Leica ${ }^{\circledR}$, Wetzlar, Germany) with Image ProPlus ${ }^{\circledR}$ software Media Cybernetics ${ }^{\circledR}$, Inc., Rockville, MD, USA) was used to take profile pictures of titanium samples. Five grade IV titanium disks were used for each surface type: machined, laser-treated, and sandblasted (Figure 2) with a Biohit $\mathrm{m} 1000^{\circledR}$ micropipette (Biohit ${ }^{\circledR}$, Helsinki, Finland). Contact angles were then calculated as described in Figure 1. 


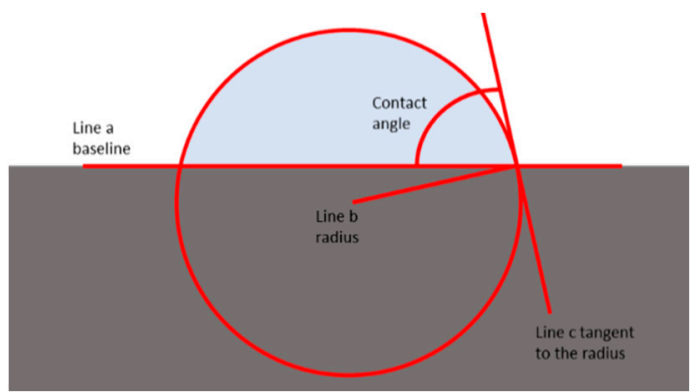

(a)

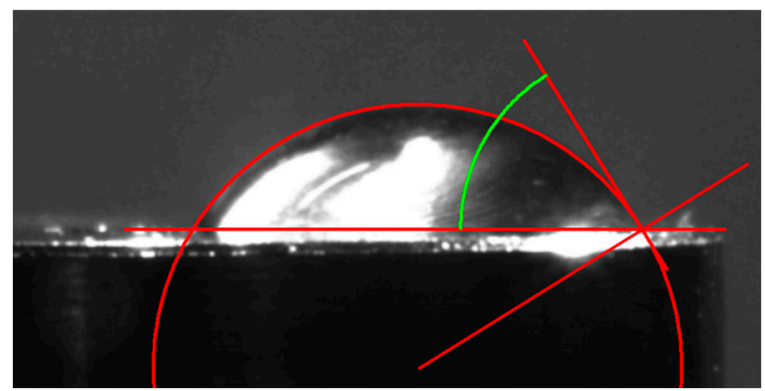

(b)

Figure 1. (a) Geometric construction for the determination of the contact angle. These reference points are straight line a, passing across the two points of contact between implant surface and the blood drop, straight line $b$, which is the radius of the circumference created by the blood drop (constructed with best fit), prolonged to intersect one of the point of intersection between the circumference and the line $a$, and the line $c$, perpendicular to line $b$ and tangential to the circumference at the point of intersection with line a. With these reference points, it is possible to calculate the angle between line $\mathrm{c}$ and line a, which corresponds to the contact angle between the blood drop and the surface. The smaller is the angle, the greater is the adhesion of the drop, and therefore the greater is the wettability. (b) Picture was taken with Leica FDC 320®camera (Leica ${ }^{\circledR}$, Wetzlar, Germany) set on an optical microscope Leica MZ16 $\left(\right.$ Leica ${ }^{\circledR}$, Wetzlar, Germany). Reference points in the picture were marked with Image ProPlus ${ }^{\circledR}$ software (Media Cybernetics ${ }^{\circledR}$, Rockville, MD, USA).

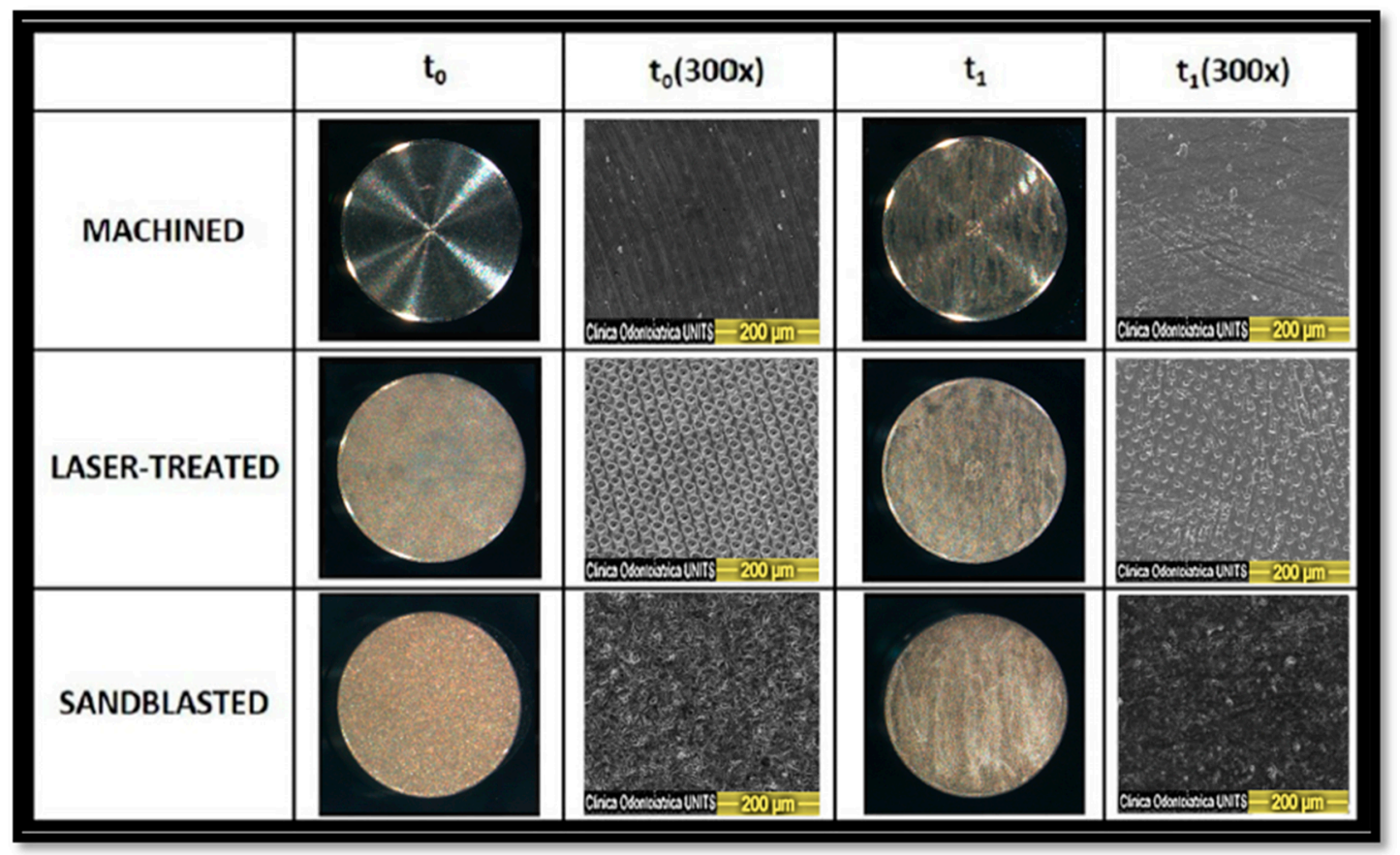

Figure 2. $3 \times$ and $300 \times$ magnification of brand new titanium surfaces before instrumentation $\left(\mathrm{t}_{0}\right)$ and after instrumentation $\left(t_{1}\right) .300 \times$ magnification was obtained with a scanning electron microscope (SEM) (Quanta 250 SEM $^{\circledR}$, FEI Company $^{\circledR}$, Hillsboro, OR, USA). Considering the laser-treated $300 \times$ micrographs, it seems that this surface is the one that maintains its "grid structure" characterized by regular roughness.

In step 2, disks were instrumented as here described: the entire top surface of the titanium disks was instrumented with an Acteon Implant Protec $t^{\circledR}$ ultrasonic grade IV titanium tip (Acteon India ${ }^{\circledR P v t}$ Ltd., Gurugram Haryana, India) set on a Satelec ${ }^{\circledR}$ scaler (Satelec ${ }^{\circledR}$ Sas, Merignac, Cedex, France) for a total of 40 strokes by a single operator (FF). The scaler tip was angulated tangentially, and care was taken to exert minimal lateral pressure. Calibrations were performed before the experiment, and the average force applied in this study was $30 \mathrm{~g}$. The back-and-forth movement was performed in the same direction for 40 strokes. Scaler power of 3/10 was applied at 25 to $32 \mathrm{kHz}$ frequency. Samples were 
then thoroughly air-dried, and a $4 \mu \mathrm{L}$ blood drop was put on them. Contact angles were then calculated.

In step 3, PRF was applied to the (previously instrumented) disks by completely soaking them in it. Samples were then dried with sterile gauze [29]. An amount of $4 \mu \mathrm{L}$ of blood was dropped on the samples. Contact angles were then calculated.

In step 4, a 30-second phosphoric acid (38\%) etching was performed on the (previously instrumented) surfaces. Samples were then washed with saline solution $0.9 \%$ for $20 \mathrm{~s}$ and thoroughly dried with compressed air. An amount of $4 \mu \mathrm{L}$ of blood was dropped on them, and contact angles were then calculated.

This 4-step procedure was performed on all 15 samples.

Data were represented as average and standard deviation. Statistical analyses were performed utilizing Origin ${ }^{\circledR}$ software (OriginLab Corporation ${ }^{\circledR}$, Northampton, MA, USA).

Kolmogorov-Smirnov test was performed. The comparisons of normally distributed data that respected the homoscedasticity of variances (Levene test) were analyzed with the one-way ANOVA test, applying Tukey's correction. Data that did not satisfy the homoscedasticity of variances were analyzed by Kruskal-Wallis and Mann-Whitney nonparametric tests with Bonferroni's correction. Statistical significance was pre-set at $\alpha=0.05$.

\section{Results}

Contact angle values are reported comparing the three implant surfaces (Figure 3a) and the four experiment steps (Figure $3 b$ ). Regarding machined titanium surfaces, after ultrasonic instrumentation, wettability decreased $\left(47.39^{\circ} \pm 13.19^{\circ}\right.$ to $\left.56.58^{\circ} \pm 12.93^{\circ}\right)$. PRF coating increased wettability $\left(33.66^{\circ} \pm 03.28^{\circ}\right)$ with respect both to instrumented and brand-new samples. By pre-etching with phosphoric acid $38 \%$ wettability increased $\left(28.62^{\circ} \pm 02.16^{\circ}\right)$ to the highest level for the machined group, superior to PRF pre-treatment, too. Regarding laser-treated titanium surfaces $\left(43.62^{\circ} \pm 08.17^{\circ}\right.$ to $\left.51.01^{\circ} \pm 03.43^{\circ}\right)$, after ultrasonic instrumentation, wettability decreased. PRF increased wettability $\left(32.87^{\circ} \pm 01.67^{\circ}\right)$ compared to instrumented and brand new average values. By pre-etching with phosphoric acid, wettability increased $\left(28.26^{\circ} \pm 01.51^{\circ}\right)$ to its highest level for the laser-treated group, superior to PRF pre-treatment, too. Regarding sandblasted titanium surfaces $\left(43.26^{\circ} \pm 12.85^{\circ}\right.$ to $\left.76.46^{\circ} \pm 07.01^{\circ}\right)$, after ultrasonic instrumentation, wettability decreased. The average value with PRF increased wettability $\left(38.83^{\circ} \pm 08.43^{\circ}\right)$ with respect both to instrumented and brand-new average values. By pre-etching with phosphoric acid, wettability increased $\left(25.74^{\circ} \pm 02.16^{\circ}\right)$ to its highest level for the sandblasted group, superior to PRF pre-treatment, too.

\section{Statistical Analysis}

All the data satisfied the normality (Kolmogorov-Smirnov test). The homoscedasticity of variances (Levene test) was verified in all the comparisons except for comparing the treatments in the laser-treated group.

Despite the low number of samples analyzed, reliable measurements of contact angle, with low variability, could be obtained. Regarding the four study steps, no significant difference was found between machined, laser-treated, and sandblasted groups, except for study step 2 (after instrumentation). A significant difference was found between the sandblasted and machined group and between the sandblasted and laser-treated group.

Regarding the 3 surface types, in the laser-treated surface, there was no significant difference between each step. Regarding the machined surface, there was a significant difference between instrumented and PRF, between non-instrumented and etched, and between the instrumented and etched group. A statistically significant difference was found regarding the sandblasted surface, between non-instrumented and instrumented and etched steps (Figure 3). 


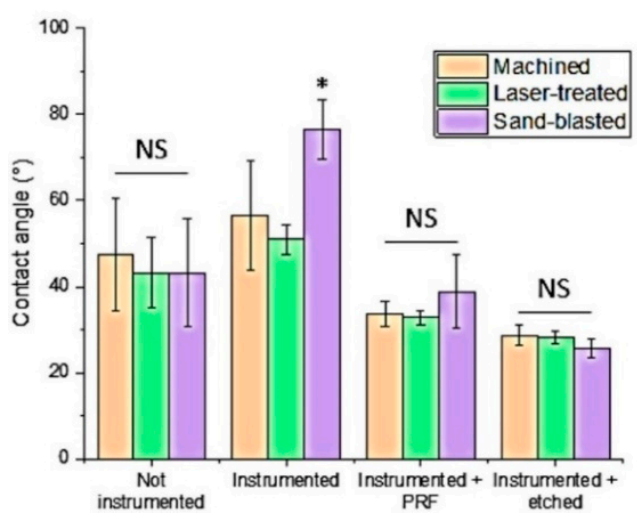

(a)

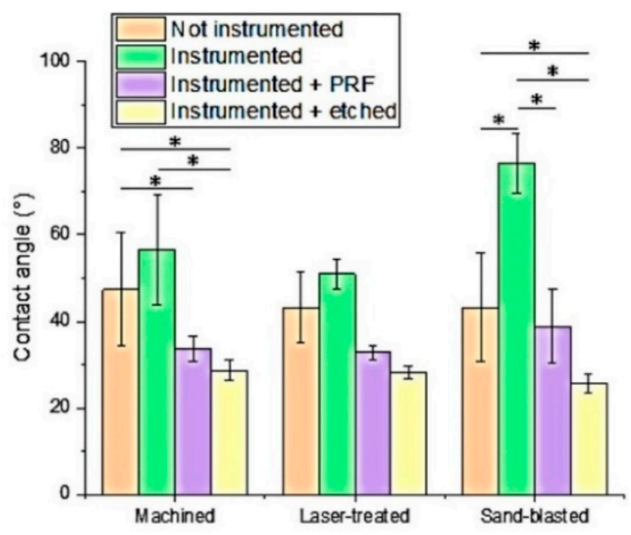

(b)

Figure 3. (a) Histogram comparing the three implant surfaces. No significant difference was found between machined, lasertreated, and sandblasted surfaces within brand new, platelet-rich fibrin (PRF), and etched groups. A statistically significant difference was found within the instrumented group between sandblasted and machined and between sandblasted and laser-treated surfaces. (b) Histogram comparing the four experiment steps. No significant difference was found within the laser-treated surface. Significant differences were found within machined surfaces (between brand new and etched, instrumented and etched, instrumented and PRF groups) and sandblasted surfaces (between brand new and instrumented, brand new and etched, instrumented and PRF, instrumented and etched groups). Statistically significant differences between samples are reported with an asterisk $\left({ }^{*}, p<0.05\right)$; NS: Not significant."

\section{Discussion}

In the current study, wettability decreased after titanium tip ultrasonic instrumentation and increased after PRF pre-treatment to a level superior to the untreated samples. Duske et al. (2012) used a cold atmospheric pressure gas-discharge plasma to reduce water contact angles on titanium disks with different surface topography: machined, SLA ${ }^{\circledR}$, SLActive $^{\circledR}$, diamond bur-treated or Airflow ${ }^{\circledR}$-treated. They found out that the contact angles of titanium disks (baseline values: $68^{\circ}-117^{\circ}$ ) were significantly reduced close to $0^{\circ}$ irrespective of surface topography after the application of argon plasma with $1.0 \%$ oxygen admixture for $60 \mathrm{~s}$ or $120 \mathrm{~s}$. The device used emits a cold flame. Temperature measurement yielded $42^{\circ}$ at the tip of the plasma jet [30] potentially permitting its use in the clinical environment. Montazeri et al. 2019 applied blood, fetal bovine serum and phosphate-buffered saline (PBS) on (brand-new) commercial implants. Wettability increased from no coating control group $\left(74.7^{\circ} \pm 3.683^{\circ}\right)$ to its highest level after blood coating $\left(10.4^{\circ} \pm 0.747^{\circ}\right)[31]$.

Phosphoric acid (38\%) etching resulted in an increased wettability with respect to PRF pre-treatment. The authors found out that this trend is the same on smooth machined and irregular roughness sandblasted surfaces; this aspect can be useful if applied to the clinical environment. If a patient comes to the hospital with peri-implantitis, the clinician might not be able to know what kind of surface he is dealing with, considering that many implant systems are present on the market. The current study suggests that ultrasonic instrumentation and then PRF or phosphoric acid etching are a valid strategy to be applied in all cases. In a parallel study of the authors, we performed energy-dispersive X-ray spectroscopy (EDX). We found out that particulate left by utilizing grade IV titanium ultrasonic tip on grade IV titanium specimens left a particulate mainly composed of titanium [32]. This fact could be interesting, considering the biocompatibility of titanium. In the literature, there are some in vivo studies in which smooth machined brand new fixtures undergo sandblasting and acid etching. After that, implants are placed on the animal bone (rats or rabbits) to study the primary osseointegration [33-35]. In vitro studies on the same topic are present, too [36-39].

The current study differs because we etched a surface previously instrumented to simulate an implant already affected with peri-implantitis. In the current study, we chose 
to use phosphoric acid ( $38 \%$ ) because it is also a frequently used chemical in the dental office, particularly in restorative dentistry.

Surface roughness difference between brand new and instrumented surfaces is a topic of a parallel study [32]. We observed a roughness decrease in laser-treated and sandblasted surfaces and a non-significant increase in machined surfaces. SEM laser-treated surfaces maintained their original micropatterned aspect. Regarding the clinical aspect, the surface conditioning technique by titanium grade IV instrumentation ultrasonic tip (same hardness) created a particulate mainly made of titanium, and for the sandblasted one, a few traces of alumina are observed. In the literature, titanium has been reported to cause foreign body reactions, too, also considering that particulate is not aseptic in the peri-implant niche.

The surface conditioning technique by using PRF coating permits avoiding the release of particulate matter. Both PRF coating and etching implant surface techniques are easy dental procedures and are not expensive. The use of PRF coating, instead of other materials also entails low morbidity. Increasing wettability by conditioning exposed implant surface favors the coat formation. Even though implant conditioning by PRF or etching increase wettability, ultrasonic instrumentation should be preceded to clean the surfaces from calculus/dental plaque, so that PRF or phosphoric acid can properly adhere to the titanium surfaces.

A limit of the current study is that it is focused on the chemical surface aspect. Further biological investigation is needed, i.e., with osteoblast cell models to evaluate adhesion, proliferation and extracellular matrix synthesis. Histological analyses focused on the investigation of cell attachment and subsequently with growth and bone growth and apposition on the implant, will be useful to determine the proper surface roughness. This will be the object of a future study. Another limit of our study is that sandblasted samples were used, whereas nowadays the SLA (Sandblasted Large-grid Acid-etched) surface is the most common surface modification in dental implants; this choice was taken in order to focus the investigation on the chemical surface aspect, starting from the same type of surface, which varied only for the roughness.

\section{Conclusions}

Increasing wettability was observed regardless of implant surface type, smooth or irregular-rough, even though the surfaces considered were already instrumented with ultrasonics. This is applicable to the clinical environment because if a patient comes to the hospital with peri-implantitis, the clinician does not know—considering the large number of implant systems on the market-which kind of surface he is dealing with. The PRF and phosphoric acid effects do not depend on the implant factory treatment nor if it had or not been already instrumented.

PRF is also simple to produce, not expensive, and autologous with no morbidity, and phosphoric acid (38\%) is widely used in dental offices for restorative dentistry.

These aspects entail that PRF or 38\% phosphoric acid utilized for the conditioning of exposed implant surfaces can be useful in the healing of peri-implant tissues.

Author Contributions: Data curation, D.P.; Investigation, F.R.; Supervision, M.M. and L.B.; Writingoriginal draft, F.F.; Writing—review \& editing, A.F. and P.F. All authors have read and agreed to the published version of the manuscript.

Funding: This research received no external funding.

Institutional Review Board Statement: Not applicable. The study was conducted with blood collected from the same volunteer but does not contain data or information regarding patients.

Informed Consent Statement: Not applicable. The study was conducted with blood collected from the same volunteer but does not contain data or information regarding patients.

Data Availability Statement: Exclude this statement. 
Acknowledgments: The authors thank Geass ${ }^{\circledR} \operatorname{srl}\left(\right.$ Geass ${ }^{\circledR}$ srl, Pozzuolo del Friuli, UD Italy) for providing titanium disks.

Conflicts of Interest: The authors declare no conflict of interest.

\section{References}

1. Zhang, L.; Ning, C.; Teng, W.; Wang, Y. Comparison of platelet adhesion behavior on pure titanium surfaces modified by different tecniques. Zhonghua Kou Qiang Yi Xue Za Zhi 2015, 50, 565-569.

2. Vanegas-Acosta, J.C.; Landinez, P.N.S. Mathematical model of the coagulation in bone-dental implant interface. Comput. Biol. Med. 2010, 40, 791-801. [CrossRef] [PubMed]

3. Bolla, M.; Di Iorio, D.; Trubiani, O.; Murmura, G. Recenti acquisizioni in tema di trattamento delle superfici implantari: Revisione della letteratura. Symp. Odontoiatr. 2012, 7-15.

4. Berardi, D.; Colagiovanni, M.; Scoccia, A.; Raffaelli, L.; Manicone, P.F.; Perfetti, G. Evaluation of a new laser surface implant: Scanning electron microscopy / energy dispersive X-ray and X-ray photoelectron spectroscopy analyses. J. Biol. Regul. Homeost. Agents 2008, 22, 161-167.

5. Cei, S.; Karapetsa, D.; Aleo, E.; Graziani, F. Protein adsorption on a laser-modified titanium implant surface. Implant Dent. 2015, 24, 134-141. [CrossRef] [PubMed]

6. Gittens, R.A.; Scheideler, L.; Rupp, F.; Hyzy, S.L.; Geis-Gerstorfer, J.; Schwartz, Z.; Boyan, B.D. A review on the wettability of dental implant surface II: Biological and clinical aspects. Acta Biomater. 2014, 10, 2907-2918. [CrossRef] [PubMed]

7. Docplayer. Available online: https://www.sciencedirect.com/topics/materials-science/wettability (accessed on 28 November 2020).

8. Pethica, B.A. The contact angle equilibrium. J. Colloid Interface Sci. 1977, 62, 567-569. [CrossRef]

9. Choukroun, J.; Adda, F.; Schoeffler, C.; Vervelle, A. Une opportunitè en paro-implantologie: Le PRF. Implantodontie 2001, 42, $55-62$.

10. Ali, S.; Bakry, S.A.; Abd-Elhakam, H. Platelet-rich fibrin in maxillary sinus augmentation: A systematic review. J. Oral Implantol. 2015, 41, 746-753. [CrossRef]

11. Olgun, E.; Ozkan, S.Y.; Atmaca, H.T.; Yalim, M.; Hendek, M.K. Comparison of the clinical, radiographic, and histological effects of titanium-prepared platelet rich fibrin to allograft materials in sinus-lifting procedures. J. Investig. Clin. Dent. 2018, 9, e12347. [CrossRef]

12. Barbu, H.M.; Andreescu, C.F.; Comaneanu, M.R.; Referendaru, D.; Mijiritsky, E. Maxillary sinus floor augmentation to enable one-stage implant placement by using bovine bone substitute and platelet-rich fibrin. BioMed Res. Int. 2018, 2018, 6562958. [CrossRef] [PubMed]

13. Pichotano, E.C.; de Molon, R.S.; de Paula, L.G.F.; de Souza, R.V.; Marcantonio, E., Jr.; Zandim-Barcelos, D.L. Early placement of dental implants in maxillary sinus grafted with leukocyte and platelet-rich fibrin and deproteinized bovine bone mineral. J. Oral Implantol. 2018, 44, 199-206. [CrossRef] [PubMed]

14. Molemans, B.; Cortellini, S.; Jacobs, R.; Pinto, N.; Teughels, W.; Quirynen, M. Simultaneous sinus floor elevation and implant placement using leukocyte- and platelet-rich fibrin as a sole graft material. Int. J. Oral Maxillofac. Implant. 2019, 34, $1195-1201$. [CrossRef] [PubMed]

15. Öncü, E.; Kaymaz, E. Assessment of the effectiveness of platelet rich fibrin in the treatment of Schneiderian membrane perforation. Clin. Implant Dent. Relat. Res. 2017, 19, 1009-1014. [CrossRef]

16. Miron, R.J.; Zucchelli, G.; Pikos, M.A.; Salama, M.; Lee, S.; Guillemette, V.; Fujioka-Kobayashi, M.; Bishara, M.; Zhang, Y.; Wang, H.L.; et al. Use of platelet-rich fibrin in regenerative dentistry: A systematic review. Clin. Oral Investig. 2017, 21, 1913-1927. [CrossRef] [PubMed]

17. Chenchev, I.L.; Ivanova, V.V.; Neychev, D.Z.; Cholakova, R.B. Application of platelet-rich fibrin in combination of bone substitute material for alveolar ridge augmentation-A case report. Folia Med. (Plovdiv) 2017, 59, 362-366. [CrossRef] [PubMed]

18. Strauss, F.J.; Stähli, A.; Gruber, R. The use of platelet-rich fibrin to enhance the outcomes of implant therapy: A systematic review. Clin. Oral Implant. Res. 2018, 29 (Suppl. 18), 6-19. [CrossRef] [PubMed]

19. Clark, D.; Rajendran, Y.; Paydar, S.; Ho, S.; Cox, D.; Ryder, M.; Dollard, J.; Kao, R.T. Advanced platelet-rich fibrin and freeze-dried bone allograft for ridge preservation: A randomized controlled clinical trial. J. Periodontol. 2018, 89, 379-387. [CrossRef]

20. Guo, T.; Nie, R.; Xin, X.; Wang, H.; Qi, M.; Yu, K.; Wang, Y.; Du, L.; Zhou, Y. Tissue preservation through socket-shield technique and platelet-rich fibrin in immediate implant placement: A case report. Medicine (Baltimore) 2018, 97, e13175. [CrossRef]

21. Lin, C.Y.; Chen, Z.; Pan, W.L.; Wang, H.L. Effect of platelet-rich fibrin on ridge preservation in perspective of bone healing: A systematic review and meta-analysis. Int. J. Oral Maxillofac. Implant. 2019, 34, 845-854. [CrossRef]

22. Öncü, E.; Alaaddinoğlu, E.E. The effect of platelet-rich fibrin on implant stability. Int. J. Oral Maxillofac. Implant. 2015, 30, 578-582. [CrossRef] [PubMed]

23. Zhou, J.; Li, X.; Sun, X.; Qi, M.; Chi, M.; Yin, L.; Zhou, Y. Bone regeneration around immediate placed implant of molar teeth with autologous platelet-rich fibrin: Two case reports. Medicine 2018, 97, e13058. [CrossRef] [PubMed]

24. Sun, X.L.; Mudalal, M.; Qi, M.L.; Sun, Y.; Du, L.Y.; Wang, Z.Q.; Zhou, Y.M. Flapless immediate implant placement into fresh molar extraction socket using platelet-rich fibrin: A case report. World J. Clin. Cases 2019, 7, 3153-3159. [CrossRef] 
25. Blinstein, B.; Bojarskas, S. Efficacy of autologous platelet rich fibrin in bone augmentation and bone regeneration at extraction socket. Stomatologija 2018, 20, 111-118.

26. Ibraheem, W. Effect of platelet-rich fibrin and free gingival graft in the treatment of soft tissue defect preceding implant placement. J. Contemp. Dent. Pract. 2018, 19, 895-899. [CrossRef] [PubMed]

27. Shah, R.; Shah, H.; Shetty, O.; Mistry, G. A novel approach to treat peri implantitis with the help of PRF. Pan Afr. Med. J. 2017, 27, 256. [CrossRef]

28. Mohamed, J.B.; Alam, M.N.; Singh, G.; Chandrasekaran, S.C. The management of retrograde peri-implantitis: A case report. J. Clin. Diagn. Res. 2012, 6, 1600-1602. [CrossRef]

29. Sartoretto, S.C.; Alves, A.T.; Resende, R.F.; Calans-Maia, J.; Granjeiro, J.M.; Calans-Maia, M.D. Early osseointegration driven by the surface chemistry and wettability of dental implants. J. Appl. Oral Sci. 2015, 23, 279-287. [CrossRef]

30. Duske, K.; Koban, I.; Kindel, E.; Schröder, K.; Nebe, B.; Holtfreter, B.; Jablonowski, L.; Weltmann, K.D.; Kocher, T. Atmospheric plasma enhances wettability and cell spreading on dental implant metals. J. Clin. Periodontol. 2012, 39, 400-407. [CrossRef]

31. Montazeri, M.; Hashemi, A.; Houshmand, B.; Faghihi, S. The effect of bio-conditioning of titanium implants for enhancing osteogenic activity. J. Oral Implantol. 2019, 45, 187-195. [CrossRef] [PubMed]

32. Faccioni, F.; Bevilacqua, L.; Porrelli, D.; Khoury, A.; Faccioni, P.; Turco, G.; Frassetto, A. and Maglione, M. Ultrasonic instrument effects on different implant surfaces: Profilometry, energy dispersive X-ray spectroscopy and Microbiology in vitro study. Int. J. Oral Maxillofac. Implant. 2021, in press.

33. Sul, Y.T.; Johansson, C.B.; Kang, Y.; Jeon, D.G.; Albrektsson, T. Bone reactions to oxidized titanium implants with electrochemical anion sulphuric acid and phosphoric acid incorporation. Clin. Implant Dent. Relat. Res. 2002, 4, 78-87. [CrossRef]

34. Park, J.W.; Kim, Y.J.; Jang, J.H.; Kwon, T.G.; Bae, Y.C.; Suh, J.Y. Effect of phosphoric acid treatment of titanium surface on surface properties, osteoblast response and removal of torque forces. Acta Biomater. 2010, 6, 1661-1670. [CrossRef]

35. Pontes, A.E.; de Toledo, C.T.; Garcia, V.G.; Ribeiro, F.S.; Sakakura, C.E. Torque analysis of a triple acid-etched titanium implant surface. Sci. World J. 2015, 2015, 819879. [CrossRef]

36. Maekawa, K.; Yoshida, Y.; Mine, A.; Fujisava, T.; Van Meerbeek, B.; Suzuki, K.; Kuboki, T. Chemical interaction of polyphosphoric acid with titanium and its effect on human bone marrow derived mesenchymal stem cell behavior. J. Biomed. Mater. Res. A 2007, 82, 195-200. [CrossRef] [PubMed]

37. Wu, J.; Hirata, I.; Zhao, X.; Gao, B.; Okazaki, M.; Kato, K. Influence of alkyl chain length on calcium phosphate deposition onto titanium surfaces modified with alkylphosphonic acid monolayers. J. Biomed. Mater. Res. A 2013, 101, 2267-2272. [CrossRef] [PubMed]

38. Jia, F.; Zhou, L.; Li, S.; Lin, X.; Wen, B.; Lai, C.; Ding, X. Phosphoric acid and sodium fluoride: A novel etching combination on titanium. Biomed. Mater. 2014, 9, 035004. [CrossRef]

39. Zhao, J.M.; Park, W.U.; Hwang, K.H.; Lee, J.K.; Yoon, S.Y. Biomimetic deposition of hydroxyapatite by mixed acid treatment of titanium surfaces. J. Nanosci. Nanotechnol. 2015, 15, 2552-2555. [CrossRef] 